\title{
Determinants of Cannabis Use Among Psychotics in Kinshasa, Democratic Republic of the Congo: A cross-sectional study
}

\author{
Abraham Bilongo Mifundu ${ }^{1}$, Gilbert Lelo Mananga ${ }^{1}$, Aliocha Natuhoyila Nkodila ${ }^{2,}$, \\ Pelagie Babakazo ${ }^{3}$, Gauthier Ehunu Messia ${ }^{4}$, Samuel Ma-Miezi Mampunza ${ }^{1,2}$ \\ ${ }^{1}$ Neuropsychopathological Center, University of Kinshasa, Kinshasa, Democratic Republic of the Congo \\ ${ }^{2}$ Faculty of Family Medicine, Protestant University in Congo, Kinshasa, Democratic Republic of the Congo \\ ${ }^{3}$ School of Public Health, University of Kinshasa, Kinshasa, Democratic Republic of the Congo \\ ${ }^{4}$ Faculty of Pharmacy, University of Kinshasa, Kinshasa, Democratic Republic of the Congo
}

Email address:

nkodilaaliocha@gmail.com (A. N. Nkodila)

${ }^{*}$ Corresponding author

\section{To cite this article:}

Abraham Bilongo Mifundu, Gilbert Lelo Mananga, Aliocha Natuhoyila Nkodila, Pelagie Babakazo, Gauthier Ehunu Messia, Samuel MaMiezi Mampunza. Determinants of Cannabis Use Among Psychotics in Kinshasa, Democratic Republic of the Congo: A cross-sectional study. Journal of Drug Design and Medicinal Chemistry. Vol. 7, No. 3, 2021, pp. 44-49. doi: 10.11648/j.jddmc.20210703.11

Received: July 6, 2021; Accepted: July 22, 2021; Published: August 5, 2021

\begin{abstract}
Background and aim: The relationship between cannabis use and psychosis is well established, but the determinants of this use in psychotics in developing countries are lacking. The aim of this study is to identify the determinants of cannabis use among psychotics in Kinshasa, Democratic Republic of Congo. Methods: This cross-sectional and analytical study included 321 psychotics carried at the Neuropsycho-pathological Center of the University of Kinshasa out from January 1, 2018 to December 31, 2019. The variables of interest were socio-demographic parameters, cannabis use and diagnoses of psychosis. A logistic regression model identified the determinants of cannabis use. The threshold of statistical significance was $\mathrm{p}<0.05$. Results: The mean age of cannabis users was $30.9 \pm 8.7$ years with a sex ratio of $12 \mathrm{M} / 1 \mathrm{~F}$. They represented $37 \%$ of psychotics of which $51 \%$ were of no religion and 55\% were schizophrenics, $77 \%$ had tobacco-alcohol co-use, $83 \%$ had high education level and 78\% were single. The determinants of cannabis use were male ( $\mathrm{aOR}=2.01,95 \% \mathrm{CI}: 1.27-3.18 ; \mathrm{P}<0.003)$, not belonging to a religion ( $\mathrm{aOR}: 2.43,95 \% \mathrm{CI}: 1.24-4.80 ; \mathrm{p}=0.010)$, tobacco co-consumption (aOR=9.12 95\% CI: 4.35-19.13; $\mathrm{p}<0.001)$, alcohol $(\mathrm{aOR}=4.39,95 \% \mathrm{CI}: 2.22-8.71 ; \mathrm{p}<0.001)$ and schizophrenia $(\mathrm{aOR}=2.29$ 95\% CI: 1.15-3, 19.13; $\mathrm{P}=0.019)$. Conclusion: The prevalence of cannabis use among psychotics was high. They were young male schizophrenics, without religion, single with co-consumption of tobacco and alcohol. The determinants were male gender, non-religious affiliation, tobacco-alcohol co-consumption and schizophrenia.
\end{abstract}

Keywords: Cannabis, Schizophrenia, Tobacco-alcohol Co-consumption

\section{Introduction}

The link between cannabis use and the development of psychosis is mentioned by numerous studies [1-7]. At a time when some countries are advocating the liberalization of recreational cannabis use $[8,9]$, it seems judicious to define the determinants of cannabis consumption among psychotics in order to identify the levers where the legislator can act to prevent the occurrence psychosis. The objective of this study is to identify the determinants of cannabis use among psychotics in Kinshasa, Democratic Republic of the Congo (DRC).

\section{Methods}

\subsection{Study Setting and Design}

This is a cross-sectional and analytical study of 321 cases of psychotic patients hospitalized at the Neuropsycho- 
pathological Center of the University of Kinshasa from January 1, 2017 to December 31, 2018.

\subsection{Study Population}

The study involved all records of hospitalized patients diagnosed with psychosis according to the DSM-IVTR (12). The inclusion criteria for the files were as follows: the subject must have been hospitalized in one of the four wards of the Neuropsycho-pathological Center of the University of Kinshasa, Department of Psychiatry; the file had to contain: the diagnosis of psychosis according to DSMIV-TR criteria (12), socio-demographic data (gender, age, educational level, marital status and religion), information on the concept of consumption of psychoactive substances, in particular cannabis, tobacco and alcohol. It should be noted that at Neuropsycho-pathological Center of the University of Kinshasa, the consumption of psychoactive substances, including cannabis, tobacco, alcohol and other psychoactive substances are systematically and actively researched in all patients.

\subsection{Data Collection and Procedure}

The literature review was used as a data collection technique. Thus, the data were collected using a data collection sheet comprising the variables operationally defined as follows: age (expressed in years and calculated from the date of birth and the date of entry into the Neuropsycho-pathological Center of the University of Kinshasa), gender (female, male), level of education (no schooling, primary, secondary and higher / university), religion / church affiliation (yes, no), marital status (single, and others: married / widower / divorced / common-law), consumption of cannabis (yes: consumes, no: abstinent) and other legal psychoactive substances including alcohol and tobacco (yes: consumes, no: abstinent) as well as the diagnosis psychosis according to the DSM-IVTR (brief psychotic disorder, schizophreniform disorder, schizophrenia, schizoaffective disorder, delusional disorder, unspecified psychotic disorder).

For data collection, four senior assistant physicians (second term) specializing in the Department of Psychiatry had been trained for this task. The data from each file was analyzed as the cases were identified and retained. A number was assigned to each completed form to ensure anonymity and confidentiality of data. At the end of each collection day, the completed data collection sheets were checked and validated by the principal investigator to ensure the quality of the data collected.

\subsection{Statistical Analysis}

Epi-Info version 6.04 and SPSS version 21.0 software were used for data entry and statistical analysis, respectively. Categorical variables are summarized by proportions and quantitative by measures of central tendency and dispersion. Pearson's chi-square and Fisher's exact tests were used to verify the association between cannabis use or not and other qualitative variables in the study. While Student's t test made it possible to compare the means of continuous variables between psychotic cannabis users and non-users. Logistic regression identified factors independently associated with cannabis use in psychotics. A $p$ value $<0.05$ was considered to be the threshold of statistical significance.

\subsection{Ethical Considerations}

The data were collected anonymously and confidentially. The privacy and confidentiality of the respondents were safeguarded. The three fundamental principles of ethics were respected at the time of the study, namely: the principle of respect for the person, that of beneficence, and that of justice. The protocol for this research study was conducted in accordance with the Declaration of Helsinki.

\section{Results}

\subsection{Socio-demographics Characteristics of the Study}

Table 1 showed that the mean age was $33.1 \pm 10.8$ years with a sex ratio of $2 \mathrm{H} / 1 \mathrm{~F}, 80 \%$ were of high educational level, $65 \%$ were single and $58 \%$ did not belong to any religion. Forty-three percent co-consumed tobacco and $30 \%$ alcohol. Moreover, this table shows that schizophrenia was the most frequent psychosis (44.2\%) (table 1).

Table 1. General characteristics of the study population.

\begin{tabular}{|c|c|c|}
\hline Variable & $\mathbf{N}=\mathbf{3 2 0}$ & $\%$ \\
\hline \multicolumn{3}{|l|}{ Age } \\
\hline Mean age \pm standard deviation (years) & $33.1 \pm 10.8$ & \\
\hline \multicolumn{3}{|l|}{ Gender } \\
\hline Male & 202 & 62.9 \\
\hline Female & 119 & 37.1 \\
\hline \multicolumn{3}{|l|}{ Educational level } \\
\hline Primary & 63 & 19.6 \\
\hline Secondary / university & 258 & 80.4 \\
\hline \multicolumn{3}{|l|}{ Marital status } \\
\hline Single & 210 & 65.4 \\
\hline Married / common-law & 111 & 34.6 \\
\hline \multicolumn{3}{|l|}{ Religion } \\
\hline Yes & 186 & 57.9 \\
\hline No & 135 & 42.1 \\
\hline \multicolumn{3}{|l|}{ Alcohol consumption } \\
\hline Yes & 139 & 43.3 \\
\hline \multicolumn{3}{|l|}{ No } \\
\hline \multicolumn{3}{|l|}{ Tobacco consumption } \\
\hline Yes & 97 & 30.2 \\
\hline \multicolumn{3}{|l|}{ No } \\
\hline \multicolumn{3}{|l|}{ Type of psychosis } \\
\hline Schizophrenia & 142 & 44.2 \\
\hline Brief psychotic disorder & 101 & 31.5 \\
\hline Schizophreniform disorder & 57 & 17.8 \\
\hline Disorganized disorder & 21 & 6.5 \\
\hline \multicolumn{3}{|l|}{ Cannabis use } \\
\hline No & 200 & 62.6 \\
\hline Yes & 120 & 37.4 \\
\hline
\end{tabular}

\subsection{Factors Associated with Cannabis Use}

In Table 2 we could note that the associated factors were young age, male sex, celibacy, not belonging to the region, 
schizophrenia and the co-consumption of tobacco and alcohol $(\mathrm{p}<0.05)$.

Table 2. Factors associated with cannabis use.

\begin{tabular}{|c|c|c|c|c|}
\hline Variables & Over all $n=320(\%)$ & Cannabis use $n=120(\%)$ & No Cannabis use $n=200(\%)$ & $\mathbf{P}$ \\
\hline Mean age \pm SD (years) & $33.1 \pm 10.8$ & $30.9 \pm 8.7$ & $34.4 \pm 11.7$ & 0.031 \\
\hline Gender & & & & $<0.001$ \\
\hline Male & $202(62.9)$ & $111(92.5)$ & $91(45.3)$ & \\
\hline Female & $119(37.1)$ & $9(7.5)$ & $110(54.7)$ & \\
\hline Educational level & & & & 0.277 \\
\hline Primary & $63(19.6)$ & $21(17.5)$ & $42(20.9)$ & \\
\hline Secondary / university & $258(80.4)$ & $99(82.5)$ & $159(79.1)$ & \\
\hline Marital status & & & & $<0.001$ \\
\hline Single & $210(65.4)$ & $94(78.3)$ & $116(57.7)$ & \\
\hline Others (married. Widowed. Divorced) & $111(34.6)$ & $26(21.7)$ & $85(42.3)$ & \\
\hline Religion & & & & 0.010 \\
\hline Yes & $186(57.9)$ & $59(49.2)$ & $127(63.2)$ & \\
\hline No & $135(42.1)$ & $61(50.8)$ & $74(36.8)$ & \\
\hline \multicolumn{5}{|l|}{ Co-consumption of SPA } \\
\hline Alcohol & $139(43.3)$ & $92(76.7)$ & $47(23.4)$ & $<0.001$ \\
\hline Tobacco & $97(30.2)$ & $79(65.8)$ & $18(9.0)$ & $<0.001$ \\
\hline \multicolumn{5}{|l|}{ Types of psychosis } \\
\hline Schizophrenia & $142(44.2)$ & $66(55.0)$ & $76(37.8)$ & 0.004 \\
\hline Brief psychotic disorder & $101(31.5)$ & $31(25.8)$ & $70(34.8)$ & 0.120 \\
\hline Schizophreniform disorder & $57(17.8)$ & $19(15.8)$ & $38(18.9)$ & 0.581 \\
\hline Disorganized disorder & $21(6.5)$ & $4(3.3)$ & $17(7.5)$ & 0.362 \\
\hline
\end{tabular}

\subsection{Determinants of Cannabis Use}

As shown in Table 3, in univariate analysis, the factors significantly associated with cannabis use are: male sex, nonreligious affiliation, alcohol and tobacco use, and schizophrenia. After adjustment, male gender, non-religious practice, alcohol and tobacco use, and schizophrenia emerged as independent determinants of cannabis use among psychotics. The measurement of the strength of association shows that the male sex $(p<0.001)$, the absence of the practice of religion $(\mathrm{p}=0.010)$, the consumption of alcohol $(p<0.001)$, tobacco $(p<0.001)$ and schizophrenia $(p=0.019)$ respectively multiply the risk of using cannabis by $6,2,4,9$ and 2 times more.

Table 3. Determinants of cannabis use by psychotic patients in univariate and multivariate analysis.

\begin{tabular}{|c|c|c|c|c|}
\hline Independants fectors & $\mathbf{p}$ & Unadjusted OR (IC95\%) & $\mathbf{p}$ & Adjusted OR (IC95\%) \\
\hline \multicolumn{5}{|l|}{ Gender } \\
\hline Female & & 1 & & 1 \\
\hline \multicolumn{5}{|l|}{ Religion } \\
\hline Oui & & 1 & & 1 \\
\hline \multicolumn{5}{|l|}{ Alcohol use } \\
\hline Yes & $<0.001$ & $10.76(6.31-18.37)$ & $<0.001$ & $4.40(2.22-8.71)$ \\
\hline \multicolumn{5}{|l|}{ Tabacco use } \\
\hline No & & 1 & & 1 \\
\hline Yes & $<0.001$ & $19.59(10.60-36.19)$ & $<0.001$ & $9.12(4.35-19.13)$ \\
\hline \multicolumn{5}{|l|}{ Schizophrenia } \\
\hline No & & 1 & & 1 \\
\hline Yes & 0.003 & $2.01(1.27-3.18)$ & 0.019 & $2.29(1.15-4.59)$ \\
\hline
\end{tabular}

\section{Discussion}

The subjects of this study were young adult, single, highly educated men who did not belong to any religion. This sociodemographic profile is described in the literature [11-18]. These socio-demographic characteristics constitute factors of vulnerability for these subjects [19]. Adulthood for Congolese men is a period of great vulnerability linked to fulfillment of social roles relating to the production of goods [20]. Celibacy, high education and non-belonging to a religion may reflect a lack of integration into social networks capable of offering social support in the event of distress (2023). In addition, the subjects of this study had polyconsumption associated cannabis-tobacco-alcohol. This association is the most commonly reported in many cannabis studies [11-15]. It can be used concomitantly [24] or simultaneously [5]. Schizophrenia is the most common psychosis in the subjects of this study, as other studies have shown $[11-15,18]$. This finding supports that of studies that report cannabis to be a risk factor for development. schizophrenia [1-3, 18]. 
A frequency of cannabis use of $37 \%$ was found in this study. This frequency is similar to that reported by Gues Ch. Et al. (2003) in Tunisia [15] and by Rodriuéz-Jiménez R. et al. (2008) in Iran [16], but it is lower than those noted in previous studies carried out in rural and urban Congolese areas (If this frequency reflects the extent of current consumption and can serve as a reference in monitoring the evolution of cannabis use among psychotics in Kinshasa, the disparity noted could be the witness of a weak recourse to modern health structures linked in particular to socio-cultural [26] and economic [27] factors. In this study, young age, male gender, non-religious affiliation, celibacy, multiple cannabis-tobacco-alcohol use, and schizophrenia were associated with cannabis use. Several studies have reported similar observations regarding the association of young age, male gender, celibacy, multiple cannabis / tobacco / alcohol use, and schizophrenia [11-15, 18] with cannabis use. To our knowledge, non-religious affiliation as a factor associated with psychosis in cannabis users has not been reported in the literature. In the present study, the determinants of use were male sex, non-religious affiliation, multiple cannabis / tobacco / alcohol use, and schizophrenia. In the DRC, men are more exposed to stress due to the expectations of the community in relation to their role in the production of goods, while women are protected by society, which prepares them for the management of goods produced by men [20]. Thus, the role of not belonging to a religion in the consumption of cannabis can be understood as an absence of recourse to a group to regulate behavior, of social support in the event of distress [21, 22] and of help for 'stopping or reducing consumption [23]. Poly-drug use involving cannabis / tobacco / alcohol is an observation usually found in studies on cannabis [11-15]. Consumption of cannabis is almost always associated with that of tobacco to facilitate combustion which aids the transformation of non-psychoactive9-tetrahydrocannabinolic acid into $\Delta$-9-tetrahydrocannabinolic [28], the main psychoactive substance in cannabis and thus prolong and increase the effects of cannabis [29]. However, several hypotheses are put forward to understand this association, in particular that of the footbridge [30], that of the inverted footbridge [31], that of a shared genetic, environmental and social vulnerability [32] and a common route of administration [33]. In the combination of cannabis and alcohol, CB1 receptors contribute to the motivational and enhancing properties of ethanol while chronic ethanol consumption alters the expression of the endocannabinoid system and that of the CB1 receptors [25]. The schizophrenia found as a determinant in this study is consistent with the observation of many other studies [18, 3436]. Furthermore, this result gives comfort to studies which report that cannabis use is very common in schizophrenics and that the relationship between cannabis and bidirectional schizophrenia [18, 35-39]. Schizophrenics are more likely to use cannabis.

\section{Limitations and Strengths of the Study}

This study has certain limitations. These limitations are linked firstly to the data collection technique used which was a documentary review. This technique leads to several biases, namely the information bias due to the fact of nonstandardization in the measurement of variables as well as the reliability of certain measurements. This technique also exposes to selection bias as there are patient charts which sometimes lack data on certain variables of interest. Second, the limitations are related to the type of study that was crosssectional. Cross-sectional studies cannot establish the time sequence between exposure and disease.

Beyond these limits, this study is among the first to have identified the factors associated with cannabis use among psychotics and thus drew the attention of healthcare providers to systematically research cannabis use among psychotics in general. and schizophrenics, in particular, and to develop supportive actions integrating cannabis addiction and psychosis.

\section{Conclusion}

Cannabis consumption among psychotics is high, particularly among young schizophrenic males, without religion, single with co-consumption of tobacco-alcohol. The determinants are the male sex, not belonging to a religion, the co-consumption of tobacco and alcohol and schizophrenia. These data suggest the systematic identification of cannabis use in any psychotic and the relevance of large-scale prospective studies to better elucidate the contextual elements of the relationship between cannabis use and psychosis.

\section{Authors' Contribution}

All authors contributed to data analysis, drafting or revising the article, have agreed on the journal to which the article will be submitted, gave final approval of the version to be published, and agree to be accountable for all aspects of the work.

\section{Conflict of Interest}

The authors declare no conflicts of interest for this work.

\section{References}

[1] Hequet, C., Murray, R., Linszen, D. et van Os, J. (2005). The environment and schizophrenia: The role of cannabis use. Schizophrenia Bulletin. 2005; 31, 3: 608-612.

[2] Semple, D. M., McIntosh, A. M. et Lawrie, S. M. Cannabis as a risk factor for psychosis: Systematic review. Journal of Psychopharmacology. 2005; 19, 2: 187-194.

[3] Moore, T. H., Zammit, S., Lingford-Hughes, A., Barnes, T. R. Jones, P. B., Burke, M. et Lewis, G. Cannabis use and risk of psychotic or affective mental health outcomes: A systematic review. Lancet. 2007; 370, 9584: 319-328.

[4] Large M, Mullin K, Gupta P, Harris A, \& Nielssen O. Systematic meta-analysis of outcomes associated with psychosis and co-morbid substance use. Aust N Z J Psychiatry. 2014; 48: 418-432. 
[5] Marconi A, Di Forti M, Lewis CM, Murray RM, Vassos E. Meta-analysis of the association between the level of cannabis use and risk of psychosis. Schizophr Bull. 2016; 42, 5: 1262-9.

[6] Myles H, Myles N, Large M. Cannabis use in first episode psychosis: Meta-analysis of prevalence, and the time course of initiation and continued use. Australian \& New Zealand Journal of Psychiatry. 2016; 50, 3: 208-19.

[7] Gage SH., Jones HJ, Burgess S, Bowden J, Davey Smith G., Zammit S, Munafo. Assessing causality in associations between cannabis use and schizophrenia risk: a two-sample Mendelian randomization study. Psychol Med. 2017; 47, 5: 971-980.

[8] Maag V. Dépénalisation de la consommation du cannabis: expériences en Europe occidentale, aux Etats-unis et en Australie. Drogues, santé et société 2004; 2, 2: 1-6.

[9] Goullé JP., Guerbet M. L'usage récréatif du cannabis: des effets aux méfaits. Données épidémiologiques. Bull Acad Natl Med. 2020; 204, 6: 543-550.

[10] American Psychiatric Association. Manuel diagnostique et statistique des troubles mentaux (DSM IV-TR).2013; 5e édition, Paris: Masson.

[11] Mifundu B. A. Profil socio-clinique des patients cannabiques hospitalisés aux CNPP/MA Mémoire de fin de spécialisation en neuropsychiatrie. Université de Kinshasa; 1995.

[12] Mifundu B. A., Mampunza M. M. S. Prise en charge des cannabiques en médecine traditionnelle à Kinshasa. Cas du Centre Mbemba Yulu, Congo médical. 1999; 11, 10: 687-690.

[13] Okitundu L. E. A., Mifundu B. A.. Cannabisme et troubles mentaux en milieu rural zaïrois. Aspects épidémiologiques. Médecine d'Afrique Noire, 1995; XXXII, 5 de mai 1995.

[14] Okitundu L. E. A., Mifundu B. A. Lusamba M. (1999). L'état de santé mentale des cannabiques et facteurs psychopathologiques en milieu rural au Kasai-Occidental (RDC) 1999; 11, 11: 775-760.

[15] Geus Ch., De Longueville X. et Schepens. Troubles psychotiques et usage de cannabis: Etude rétrospective. Louvain Médical 2004; 123: 14-17.

[16] Rodriguez-Jimenez R, Aragues M, Jimenez-Arriero MA, Ponce G, Munoz A, Bagney A, et al. Dual diagnosis in psychiatric inpatients: prevalence and general characteristics]. Invest Clin. 2008; 49, 2: 195-205.

[17] Guillem E, Pelissolo A., Vorspan F., Bouchez-Arbabzadeh S., Lépine J-P. Facteurs sociodémographiques, conduites addictives et comorbidité psychiatrique des usagers de cannabis vus en consultation spécialisée. L' Encéphale 2009; $35,3: 226-233$.

[18] Koskinen, J., Lohonen, J., Koponen, H., Isohanni, M. et Miettunen, J. Rate of cannabis use disorders in clinical samples of patients with schizophrenia: A meta-analysis. Schizophrania Bulletin. 2010; 36, 6: 1115-1130.

[19] Institut National de la Santé et de la Recherche Médicale (INSERM). Synthèse et recommandations. «Cannabis. Quels effets sur le comportement et la santé?». Données réactualisées en 2004. Expertise collective. 2004, 4 pages.

[20] Lututala M. B. et Ngondo a P. Gender and Education for All: The Leap to Equality "Paper commissioned for the EFA
Global Monitoring Report 2003/4, The Leap to Equality". 2003, 11.

[21] Bruchon- schweitzer M. Psychologie de la santé: modèles, concepts et méthodes. Dunod, Paris 2002.

[22] Sanchez Z, Oliveira LG and Nappo SA. Religiosity as a protective factor against use of drugs. Substance use and misuse 2008; 43: 1476-1486.

[23] Petry NM, Lewis MW, Ostvik-White EM: Participation in religious activities during contingency management interventions is associated with substance use treatment outcomes. Am J Addict 2008; 17: 408-13.

[24] Ramo DE, Liu H, Prochaska JJ. Tobacco and marijuana use among adolescents and young adults: a systematic review of their co-use. Clinical Psychology Review. 2012; 32, 2: 105121.

[25] Subbaraman MS, Kerr WC. Simultaneous versus concurrent use of alcohol and cannabis in the national alcohol survey. Alcohol Clin Exp Res. 2015; 39, 5: 872-9.

[26] Mifundu B. A., Mampunza M. M. S. Cannabisme et cannabique: Perception de l'entourage familial. Annales de l'IRS 1998; 2: 41-42.

[27] Ministère du Plan. Document de la Stratégie de Croissance et de Réduction de la Pauvreté, 2011, 92.

[28] Dussy FE, Hamberg C, Luginbuhl M, Schwerzmann T, Briellmann TA. Isolation of Delta9-THCA-A from hemp and analytical aspects concerning the determination of Delta9THC in cannabis products. Forensic Sci Int. 2005; 149, 1: 310 .

[29] Arpana Agrawal and Michael T. Lynskey. Tobacco and Cannabis Co-occurrence: Does Route of Administration Matter? Drug Alcohol Depend. 2009 January 1; 99, 1-3: 240247.

[30] Kandel DB, Yamaguchi K, Chen K. Stages of progression in drug involvement from adolescence to adulthood: further evidence for the gateway theory. J Stud Alcohol. 1992; 53, 5: 447-457.

[31] Patton GC, Coffey C, Carlin JB, Sawyer SM, Lynskey M. Reverse gateways? Frequent cannabis use as a predictor of tobacco initiation and nicotine dependence. Addiction 2005; 100: 1518-1525.

[32] Power RA., Verweij KJ, Zuhair M, et al. Genetic predisposition to schizophrenia associated with increased use of cannabis. Mol Psychiatry. 2014; 19, 11: 1201-1204.

[33] Agrawal A, Lynskey MT. Tobacco and cannabis cooccurrence: does route of administration matter? Drug Alcohol Depend. 2009; 99, (1-3): 240-247.

[34] Mueser KT, Yarnold PR, Levinson DF, et al. Prevalence of substance abuse in schizophrenia: demographic and clinical correlates. Schizophr Bull. 1990; 16: 31-55.

[35] Hunt GE, Large MM, Cleary M, et al. Prevalence of comorbid substance use in schizophrenia spectrum disorders in community and clinical setting, 1990-2007: systematic review and meta-analysis. Drug Alcool Depend. 2018; 191: 234-258.

[36] McLoughlin BC, Pushpa-Rajah JA, Gillies D, et al. Cannabis and schizophrenia. Cochrane Database Systt Rev. 20014; 10. 
[37] Dervaux A, Laqueille X, Le Borgn MH et al Cannabis et schizophrénie: données cliniques et sociodémographiques, L'Encéphale 2003; 29: 11-17.

[38] Dervaux A., Krebs M-O., Laqueille X. Les troubles cognitifs et psychiatriques liés à la consommation de cannabis Bull. Acad. Natle Méd. 2014; 198, 3: 559-577.
[39] Potvin, S., Stip, E. \& Roy, J.-Y.. Schizophrénie et cannabinoïdes: données cliniques, expérimentales et biologiques. Drogues, santé et société 2000; 2, 2. 